\title{
Incidence of Eczema in Early Infancy and the Prenatal Risk Factors - Guangzhou, Guangdong, China, 2018-2019
}

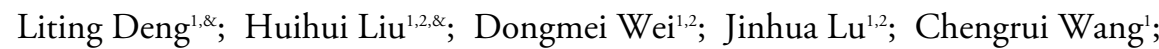 \\ Songying Shen ${ }^{1}$; Jianrong $\mathrm{He}^{1,2}$; Xiu $\mathrm{Qiu}^{1,2, t}$
}

\begin{abstract}
Summary
What is already known on this topic?

Eczema is a common allergic disease in children, which seriously affects the quality of life of children and their families.

What is added by this report?

The results showed that the incidence of very-earlyonset eczema was $12.4 \%$. Primiparity was associated with a higher risk of eczema [risk ratio (95\% confidence interval): 1.23 (1.06-1.42)].

What are the implications for public health practice?

Very-early-onset eczema is common. Given its adverse impact on children's health and life quality, this previously neglected public health issue needs to be prioritized. In addition, maternal parity could serve as an indicator in risk assessment and prediction for infant eczema.
\end{abstract}

Eczema is a common chronic disease in children, characterized by recurrent episodes of skin lesion and pruritus (1). Eczema is the first manifestation of "atopic march" and can lead to a higher risk of developing other allergic diseases later in life (2). However, the epidemiologic characteristics of eczema in very early life are still unclear. This study estimated the incidence of very-early onset of eczema, defined as diagnosed before six weeks of age, among infants born in Guangzhou, China, between 2018 and 2019, and it explored its related prenatal risk factors. The incidence of very-early-onset eczema was $12.4 \%$ in this population, and primiparity was associated with a higher risk of eczema \{relative risk (RR) [95\% confidence interval (CI)]: $1.23(1.06-1.42)\}$. These findings indicate prenatal factors could have an important role in the development of infant eczema. The high incidence of infant eczema should receive more attention, and more research is needed to investigate the etiology of infant eczema and explore potential primary prevention strategies.
The present study was based on data collected from the Born in Guangzhou Cohort Study (BIGCS), which is a prospective birth cohort study conducted by the Guangzhou Women and Children's Medical Center (GWCMC), China. Women were recruited during their first routine antenatal appointment $(<20$ weeks of gestation) at two different sites of GWCMC. Motherinfant dyads were included for this analysis if the infant was born between January 2018 and December 2019 and completed a follow-up at six weeks of age. Exclusion criteria excluded mothers with multiple pregnancies, withdrawn from the study after delivery, or whose infants died during the first six weeks postpartum. The Institute Ethics Committee of GWCMC has approved the study, and all participants provided written informed consent at enrollment.

The outcome of interest was very-early-onset eczema (i.e., eczema onset before 6 weeks of age). Information on infant eczema was collected via a self-administrative questionnaire modified from the validated version of International Study of Asthma and Allergies in Childhood. The parents were asked to choose yes or no to the question "has your child ever had atopic eczema diagnosed by a physician after birth?" during a followup at six-weeks postpartum. Other maternal information, including demographic characteristics, environmental exposure, and health conditions during pregnancy, was collected at enrollment via a validated questionnaire. Pre-pregnancy body mass index (BMI) $\left(\mathrm{kg} / \mathrm{m}^{2}\right)$ was categorized into four groups: underweight $\left(\mathrm{BMI}<18.5 \mathrm{~kg} / \mathrm{m}^{2}\right.$ ), normal (BMI $18.5-23.9 \mathrm{~kg} / \mathrm{m}^{2}$ ), overweight (BMI 24.0-27.9 $\mathrm{kg} / \mathrm{m}^{2}$ ), and obesity (BMI $\geq 28.0 \mathrm{~kg} / \mathrm{m}^{2}$ ) based on Chinese standards (3). Differences in participants' characteristics by infant eczema status (yes/no) were examined using the chisquared test for categorical data and Student's t-test for continuous variables. The incidence of eczema was calculated by dividing the number of infants diagnosed with eczema by the total number of infants included in the analysis. Poisson regression models were performed to investigate the association between potential risk 
factors and very-early-onset eczema, and RR and $95 \%$ CI were calculated. Statistical analyses were performed using SAS (version 9.4, SAS Institute Inc., Cary, NC, USA).

A total of 10,085 singleton-born infants [follow-up rate of $90.6 \%(10,085 / 11,130)]$ had information on eczema diagnosis at six weeks of age and were included in the current analysis. Among these infants, $12.4 \%$ $(\mathrm{n}=1,247)$ had very-early-onset eczema. Table 1 summarized the maternal and infant characteristics by very-early-onset eczema status (yes/no). The incidence of very-early-onset eczema among infants of primiparous mothers was higher than that among infants of multiparous mothers $(13.4 \%$ vs. $10.8 \%$, $P<0.01)$. Statistically significant differences were not found between infants with or without very-early-onset eczema in other maternal and infant characteristics, including maternal age, maternal monthly income, maternal education level, pre-pregnancy BMI, tobacco exposure during early pregnancy, maternal history of allergy, pets during pregnancy, proportion of cesarean section, gestational diabetes mellitus, hypertensive disorders in pregnancy, gestational age, and infant sex. Results for associations of each potential prenatal risk

TABLE 1. Maternal and infant characteristics according to very-early-onset eczema in Guangzhou, Guangdong, China, 2018-2019.

\begin{tabular}{|c|c|c|c|}
\hline Characteristics & $\begin{array}{l}\text { With very-early-onset eczema } \\
\qquad(n=1,247)\end{array}$ & $\begin{array}{l}\text { Without very-early-onset eczema } \\
\qquad(n=8,838)\end{array}$ & $P$-value \\
\hline Maternal age, years, mean $\pm S D$ & $30.5 \pm 3.8$ & $30.6 \pm 4.0$ & 0.30 \\
\hline Maternal monthly income, CNY, n (\%) & & & 0.22 \\
\hline$\leq 1,500$ & $91(8.1)$ & $685(8.4)$ & \\
\hline $1,501-4,500$ & $130(11.6)$ & $1,115(13.6)$ & \\
\hline $4,501-9,000$ & $454(40.5)$ & $3,305(40.4)$ & \\
\hline$\geq 9,001$ & $447(39.8)$ & $3,078(37.6)$ & \\
\hline Maternal education level, n (\%) & & & 0.08 \\
\hline Middle school or below & $78(6.3)$ & $721(8.2)$ & \\
\hline College & $283(22.7)$ & $2,017(22.8)$ & \\
\hline Undergraduate & $673(54.0)$ & $4,724(53.5)$ & \\
\hline Postgraduate or above & $213(17.1)$ & $1,376(15.6)$ & \\
\hline Pre-pregnancy BMI, $\mathrm{kg} / \mathrm{m}^{2}, \mathrm{n}(\%)$ & & & 0.65 \\
\hline$<18.5$ & $241(20.9)$ & $1,645(19.9)$ & \\
\hline $18.5-23.9$ & $783(68.0)$ & $5,631(68.2)$ & \\
\hline $24.0-27.9$ & $110(9.6)$ & $828(10.0)$ & \\
\hline$\geq 28.0$ & $17(1.5)$ & $155(1.9)$ & \\
\hline Tobacco exposure during early pregnancy, $\mathrm{n}(\%)$ & $323(27.1)$ & $2,309(26.8)$ & 0.85 \\
\hline Drinking during early pregnancy, $\mathrm{n}(\%)$ & $63(5.3)$ & $436(5.1)$ & 0.75 \\
\hline \multicolumn{4}{|l|}{ Maternal history of allergy, $\mathrm{n}(\%)$} \\
\hline Eczema & $81(6.8)$ & $517(6.0)$ & 0.31 \\
\hline Rhinitis & $195(16.3)$ & $1,329(15.4)$ & 0.45 \\
\hline Asthma & $9(0.8)$ & $40(0.5)$ & 0.19 \\
\hline Pets during pregnancy, $\mathrm{n}(\%)$ & $171(14.2)$ & $1,144(13.3)$ & 0.35 \\
\hline Cesarean section, $\mathrm{n}(\%)$ & $336(27.0)$ & $2,485(28.2)$ & 0.37 \\
\hline Primipara, $\mathrm{n}(\%)^{*}$ & $814(65.3)$ & $5,243(59.3)$ & $<0.01$ \\
\hline Gestational diabetes mellitus, n (\%) & $211(17.0)$ & $1,477(16.8)$ & 0.88 \\
\hline Hypertensive disorders in pregnancy, $\mathrm{n}(\%)$ & $61(4.9)$ & $401(4.6)$ & 0.59 \\
\hline Gestational age, weeks, mean \pm SD & $39.3 \pm 1.2$ & $39.2 \pm 1.4$ & 0.11 \\
\hline Male child, $\mathrm{n}(\%)$ & $672(53.9)$ & $4,603(52.1)$ & 0.25 \\
\hline
\end{tabular}

Abbreviations: $\mathrm{BMI}=$ body mass index; $\mathrm{SD}=$ standard deviation.

* Statistically significant. 
factor with very-early-onset eczema were also shown in Figure 1. Primiparity was associated with increased risk of very-early-onset eczema [RR $\left(\begin{array}{lll}95 \% & \mathrm{CI}): & 1.23\end{array}\right.$ (1.06-1.42)]. No statistically significant association was found for other prenatal factors.

\section{DISCUSSION}

This study shows that the incidence of eczema onset in very early infancy was $12.4 \%$. Parity was associated with a higher risk of very-early-onset eczema. Understanding the incidence of very-early-onset eczema and exploring its related risk factors may help facilitate early identification of the population that is at high-risk of developing allergic disease later in life and thus enable early and effective interventions.

Characteristics
Maternal age, years
Maternal monthly income, CNY
$\leq 1,500$
$1,501-4,500$
$4,501-9,000$
$\geq 9,001$
Maternal education level
Senior high school or below
College
Undergraduate
Postgraduate or above
Pre-pregnancy BMI, kg/m²
$<18.5$
$18.5-23.9$
$24.0-27.9$
$\geq 28.0$
Tobaccoexposure during early pregnancy
Drinking during early pregnancy
Maternal history of allergy
Eczema
Rhinitis
Asthma
Pets during pregnancy
Cesarean section
Primipara*
Gestational diabetes mellitus
Hypertensive disorders in pregnancy
Gestational age, weeks
Male child

The incidence of very-early-onset eczema reported in this study was at a similar level as those reported in two other studies conducted in Japan (12.1\%) (4) and in the United Kingdom (11.6\%) (5). The present finding suggests that eczema affects a substantial proportion of infants in very early life in Guangzhou City, Guangdong Province, China.

The Origin of Development of Health and Disease theory suggests that factors in early life may contribute to the development or progression of disease in childhood and later in life (G). The current study showed that infants of primiparous mothers are more likely to have very-early-onset eczema compared to those of multiparous mothers. This finding can be explained as having more siblings increased the chance of infection in early life, which could reduce the occurrence of allergies by inhibiting the proliferation of

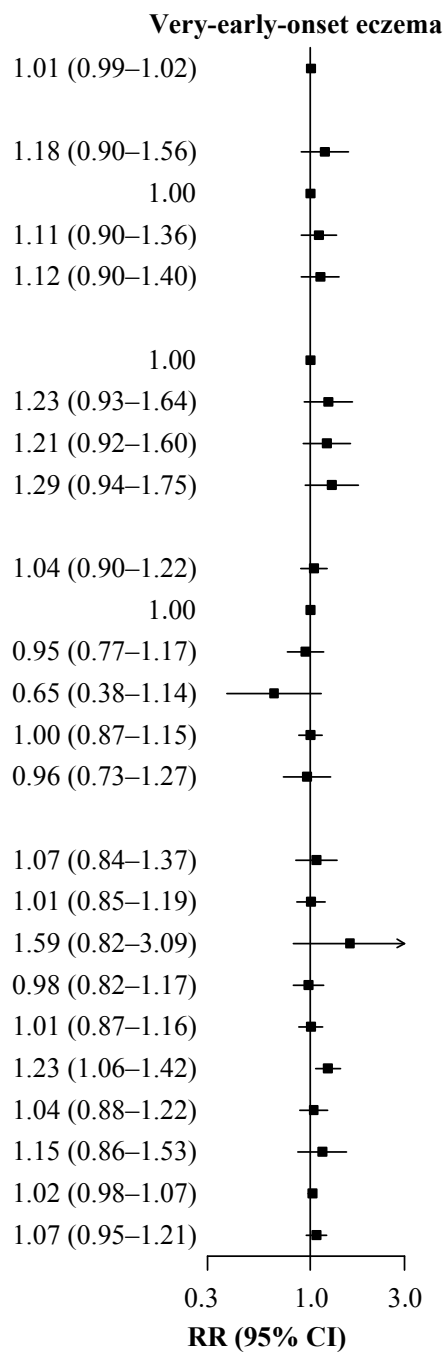

FIGURE 1. The risk factors of very-early-onset eczema in Guangzhou, Guangdong, China, 2018-2019.

Abbreviations: $\mathrm{BMI}=$ body mass index; $\mathrm{Cl}=$ confidence interval; $\mathrm{RR}=$ rate ratio.

* Statistically significant. 
Th2 cells (7).

Findings from this study have important public health implications. Although it is not a lifethreatening condition, eczema can substantially affect the patients' quality of life and may have a long-term impact on their health. According to the Global Burden of Disease study 2019, it is estimated that eczema caused about one million disability-adjusted life years in China (8). More importantly, very-earlyonset eczema is an indication of altered immune function in early life, which could increase the risk of subsequent allergic diseases. The current study found the incidence of very-early-onset eczema was as high as $12.4 \%$ in Guangzhou City in 2018-2019. This finding suggested that the prevention of early-onset eczema should be prioritized to improve child health. Furthermore, maternal parity was associated with risk of infant eczema in the present study. This finding also suggested future directions to identify populations at higher risk of developing eczema and the window of opportunity to intervene.

The current study has several strengths. The prospective cohort design likely reduced potential recall bias, and the large sample size with a low attrition rate ensured sufficient statistical power to detect a modest effect.

The study was also subject to some limitations. First, the potential residual confounding by unmeasured factors. Second, the eczema infant in the present study was assessed based on doctor's diagnosis. Thus it might only represent the severe cases that require medical attention.

In conclusion, the current study showed that the incidence of very-early-onset eczema was as high as $12.4 \%$ in Guangzhou, Guangdong, China. Infants of mothers who were primiparous had a higher risk of eczema. These findings suggested that efforts should be made to evaluate and prevent very-early-onset eczema, especially among primiparous mothers.

Acknowledgements: All participant mothers and their children in the Born in Guangzhou Cohort Study; all participating obstetric care providers who assisted in the implementation of the study; and the Born in Guangzhou Cohort Study team.

Funding: The National Natural Science Foundation of China (grant numbers 81673181), Department of Science and Technology of Guangdong Province (grant number 2019B030316014), Guangzhou Science Technology and Innovation Commission (201807010086).

doi: $10.46234 / \mathrm{ccdcw} 2021.173$

\# Corresponding author: Xiu Qiu, qiu.xiu@bigcs.org.

${ }^{1}$ Division of Birth Cohort Study, Guangzhou Women and Children's Medical Center, Guangzhou Medical University, Guangzhou, Guangdong, China; ${ }^{2}$ Department of Women and Child Health Care and Provincial Key Clinical Specialty of Woman and Child Health, Guangzhou, Guangdong, China.

\& Joint first authors.

Submitted: May 26, 2021; Accepted: June 11, 2021

\section{REFERENCES}

1. Ramirez FD, Chen S, Langan SM, Prather AA, McCulloch CE, Kidd SA, et al. Association of atopic dermatitis with sleep quality in children. JAMA Pediatr 2019;173(5):e190025. http://dx.doi.org/10.1001/jamape diatrics.2019.0025.

2. Nutten S. Atopic dermatitis: global epidemiology and risk factors. Ann Nutr Metab 2015;66 Suppl 1:8-16. http://dx.doi.org/10.1159/ 000370220 .

3. Hu LH, Huang X, You CJ, Li JX, Hong K, Li P, et al. Prevalence of overweight, obesity, abdominal obesity and obesity-related risk factors in southern China. PLoS One 2017;12(9):e0183934. http://dx.doi.org/ 10.1371/journal.pone.0183934.

4. Sugiyama M, Arakawa H, Ozawa K, Mizuno T, Mochizuki H, Tokuyama K, et al. Early-life risk factors for occurrence of atopic dermatitis during the first year. Pediatrics 2007;119(3):e716-23. http://dx.doi.org/10.1542/peds.2006-0893.

5. Ziyab AH, Ewart S, Lockett GA, Zhang H, Arshad H, Holloway JW, et al. Expression of the filaggrin gene in umbilical cord blood predicts eczema risk in infancy: a birth cohort study. Clin Exp Allergy 2017;47(9):1185 - 92. http://dx.doi.org/10.1111/cea.12956.

6. Gillman MW. Developmental origins of health and disease. N Engl J Med 2005;353(17):1848 - 50. http://dx.doi.org/10.1056/NEJMe 058187.

7. Xu B, Pekkanen J, Järvelin MR. Prenatal factors and occurrence of rhinitis and eczema among offspring. Allergy 1999;54(8):829-36. http://dx.doi.org/10.1034/j.1398-9995.1999.00117.x.

8. Global Health Data Exchange. Global burden of disease study 2019 (GBD 2019) data resources. http://ghdx.healthdata.org/gbd-results-tool. [2021-5-27]. 